Conb-900355--2

BNL--43546-Rev.

DE92 007453

\title{
CARBONACEOUS AEROSOLS FROM PRESCRIBED BURNING OF A BOREAL FOREST ECOSYSTEM
}

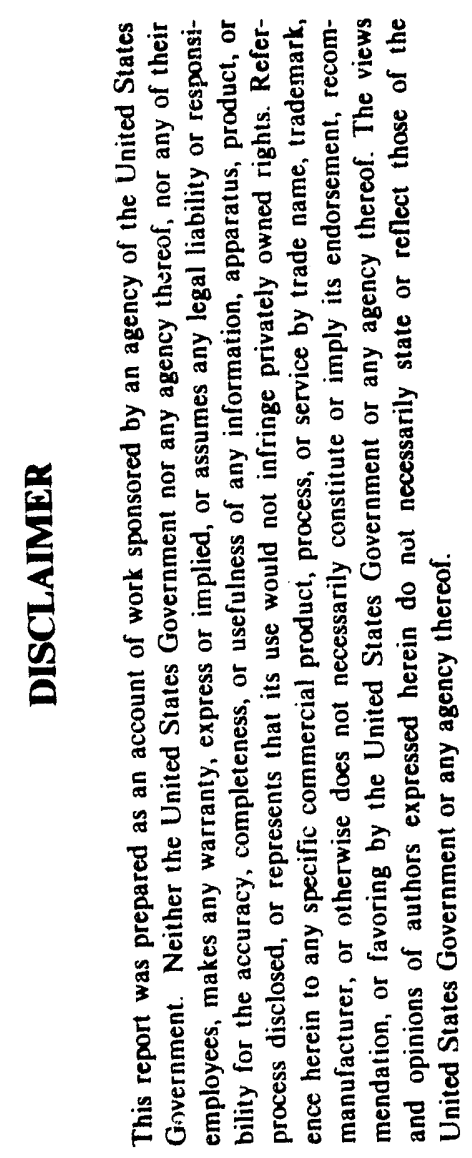

M. A. Mazurek, W. R. Cofer, $\mathrm{I}^{*}$, and J. S. Levine*

Environmental Chemistry Division

Department of Applied Science

Brookhaven National Laboratory

Upton, NY 11973

October 1990

Presented at the

Chapman Conference on Global Biomass Burning:

Atmospheric, Climate, and Biospheric Implications,

Williamsburg, VA

March 19-23, 1990

* NASA Langley Research Center, Hampton, VA 23665

By acceptance of this article, the publisher and/or recipient acknowledges the U.S. Government's right to retain a non-exclusive royalty-free license in and to any copyright covering this paper.

This research was performed under the auspices of the United States Department of Energy, under Contract No. DE-AC02-76CH00016. 


\section{ABSTRACT}

The identity and ambient mass concentrations of radiatively important carbonaceous aerosols were measured for a boreal forest prescribed bum conducted in northern Ontario, CAN in August 1989. Nonsize-segregated airbome particles were collected for smolderingfire and full-fire conditions using a helicopter sampling platform. Total carbon (TC), organic carbon $(O C)$ and elemental carbon $(E C)$ were measured. Smoke plume mass concentrations of the OC and EC particles were greatest for full-fire conditions and had ranges of 1.560 to $2.160 \mathrm{mg} / \mathrm{m}^{-1}(O C)$; 0.120 to $0.160 \mathrm{mg} / \mathrm{m}^{-3}$ (EC) with OC: $\mathrm{EC}$ ratios of 10 to 18 , respectively. Smuri Ing fire conditions showed smoke plume $O C$ and EC levels of 0.570 $1.030 \mathrm{mg} / \mathrm{m}^{-3}(\mathrm{OC})$ and $0.006-0.050 \mathrm{mg} / \mathrm{m}^{-3}(\mathrm{EC})$ arid much higher ratios of OC:EC (21 to 95). These aerosol data indicaw the formation of EC particles is greatest during full-fire combustion of boreal forest material relative to smoldering combustion. However, EC particles comprise a minor fraction of the particulate carbon smoke aerosols for both full-fire and smoldering conditions; the major component of carbonaceous smoke aerosols emitted during the prescribed burn is $O C$. Overall, the $O C$ and EC in-plume smoke aerosol data show nonuniform production of these particles during various stages of the prescribed burn, and major differences in the type of carbonaceous aerosol that is generated (OC versus EC). 


\section{INTRODUCTION}

Carbonaceous particles in the tropospheric boundary layer can both scatter and absorb solar radiation. These particles are emitted from numerous sources, including combustion of vegetative matter. Although biomass burning is now recognized as a major and increasing source of particulate carbon to the global atmosphere (e.g., Duce, 1978; Seiler and Crutzen, 1980; Andreae, 1990), the impact of these smoke aerosol emissions on tropospheric chemistry and on global climate is not well known. Much of the uncertainty is linked to the limited inventories of non-volatile carbonaceous aerosols that are emitted from biomass combustion processes, to the few measurements of smoke aerosol physical and optical properties, and to a narrow understanding of the fate and dispersal of smoke aerosol within the troposphere. Consequently, general circulation models (GCMs) have few real data on which to predict global climate change due to the changing chemical and radiative properties of the earth's atmosphere now linked, in part, to the increased emissions of carbonaceous aerosols from global biomass buming.

In the past, carbonaceous particles found in the smoke plumes of combusted biomass have been evaluated as bulk aerosol components. Two forms of smoke aerosol, organic carbon $(\mathrm{OC})$ and elemental carbon $(\mathrm{EC})$, are radiatively active components; $\mathrm{OC}$ particles scatter solar radiation (depending on composition) and EC particles scatter and absorb the same radiation. Total carbon (TC), OC, and EC have been identified in smoke from the tropics (Andreae et al., 1988; Cachier et al., 1989; Suman 1988). Recent estimates of the global emissions of particulate organic carbon and elemental carbon due to biomass burning 
show major releases to the troposphere of these radiatively important carbonaceous particles (69 Tg/yr for OC; $19 \mathrm{Tg} / \mathrm{yr}$ for EC) (Andreae, 1990).

Detailed chemical measurements which relate aerosol composition to emission sources of the carbonaceous matter contained in smoke aerosols, especially those from large scale biomass combustion, are few. Stable carbon isotope analyses $\left({ }^{13} \mathrm{C} /{ }^{12} \mathrm{C}\right.$ content) are available for smoke aerosols collected from burning of savannah grassland and tropical rainforests (Cachier et al., 1986; 1989). Significant differences are noted in the ratio of ${ }^{13} \mathrm{C} /{ }^{12} \mathrm{C}$ present in the smoke aerosol from these types of biofuels and such isotopic distinctions have been applied to source characterizations of carbonaceous aerosols in the remote marine atmosphere (Cachier et al., 1986). Standley and Simoneit $(1987,1990)$ have identified molecular tracers present in smoke aerosols sampled from prescribed burning of a coniferous forest. These organic compounds were traced directly to the coniferous biofuels, and consisted of plant waxes, resins, and thermally altered wood biopolymers. Other analytical techniques have been applied to carbonaceous subfractions of whole wood smoke emissions, aiso for source reconciliation (Hildemann 1990; Mazurek et al., 1990a,b). In these applications, the solventsoluble organic compounds isolated from wood smoke aerosol produce unique chemical profiles that serve as "fingerprints" to be used in distinguishing among different types of wood burned. Therefore, given the ability to measure key carbonaceous subfractions present in smoke aerosil which can be related chemically to the biomass fuel source, it is useful to apply these analytical methods to natural wildfire and prescribed bum emission studies.

The goal of this project consists of three objectives. First, evaluations are needed of the sampling methods and analytical techniques used in measuring smoke aerosol emissions 
from biomass combustion. Accurate quantitative measurements of particulate carbon emissions rely on sampling and analytical methods which have been evaluated fully in terms of quality assurance/quality control (QA/QC) parameters. Second, an accounting is necessary for the mass of total carbon present as smoke particles and for the subfractions which constitute the total particulate carbon aerosol mass. This chemical mass balance provides a quantitative basis for describing the mass distribution of radiatively important aerosols (OC and EC fractions) emitted during biomass burning. Finally, a third objective is to compile emission data from the combustion of diverse ecosystems, where measurements are made of carbonaceous particles, especially those that effectively scatter and absorb light. These emission data are needed to provide a global distribution of particulate carbon releases to the atmosphere due to prescribe bums, agricultural land clearing, and natural wildfires.

As an initial step toward these objectives, smoke aerosol and background aerosol particles are collected from the controlled burning of boreal forest where vegetation species and relative mass distributions are known. Chemical mass balances are consitructed for the total mass of carbonaceous aerosol particles emitted during the prescribed burn. A carbonaceous species inventory is developed for aerosol particles present under background, smoldering, and full-fire conditions; the production of $\mathrm{OC}$ and EC particles is noted for these two fire regimes. Distributions of the solvent-soluble organic components of the sampled aerosols are generated to identify molecular properties that can be traced to unburned and pyrolyzed materials present in the boreal forest fuels. 


\section{METHODS}

\section{Smoke Aerosol Collection}

A boreal forest prescribed bum ( 486 hectares) was conducted in the Hill township of northem Ontario, Canada on August 10, 1989. The fuel source composition consisted of spruce (13\%), balsam fir (25\%), white birch/poplar (46\%), decayed wood (12\%), and miscellaneous wood (4\%) (Stocks, 1990). The mass of unburned woody material was 9-10 $\mathrm{kg} / \mathrm{m}^{2}$ of which $6.6 \mathrm{~kg} / \mathrm{m}^{2}$ was consumed.

A helicopter platform configured for smoke plume sampling was used (e.g. Cofer et al., 1988). Aerosol particles that were unsegregated with respect to particle diameter were collected on prefired quartz microfiber filters (102 mm diameter). Collection times ranged between 0.5 to 4.0 minutes per sample at flow rates of $360 \mathrm{lpm}$. Several burn conditions were sampled: (1) background aerosol (out-of plume) during full-fire conditions; (2) full-fire burning in-plume aerosol; and (3) smoldering in-plume aerosol. Replicates of the full-fire and smoldering in-plume smoke aerosol were obtained to identify a range of ambient mass concentrations of the carbonaceous aerosol present during the two fire regimes. The background aerosol sample was collected as a method of evaluating the performance of the sampling equipment under dynamic conditions, and provided a check for sampling-derived artifacts, if present. A travel blank consisting of a prefired and unused filter accompanied the sampled filters. The travel blank was used to monitor storage and handling conditions that existed for the collected sample filters, and later, to assess the total analytical background of possible carbonaceous artifacts. All filters were stored and shipped in annealed borosilicate glass jars that were fitted with Teflon-lined caps. Once collected, the 
smoke aerosol samples and blank filters were frozen $(-27 \mathrm{C})$ until analysis.

Analysis

The analytical objective for this study is to construct the following mass balance relationship for the smoke aerosols collected during the prescribed bum:

Total Carbon (Organic + Elemental) : Organic Carbon : Elemental Carbon : Elutable Organics.

Several analytical methods are required for the above mass determinations: (1) total carbon analysis by a combined pyrolysis/combustion measurement technique (Johnson et al., 1981); and (2) quantitation of solvent-soluble organics (i.e., compounds having 6 to 40 carbon atoms) by high-resolution gas chromatography (HRGC) flame ionization (Mazurek et al., 1987). Measurement of these bulk carbon constituents present in smoke aerosol particles permits a quantitative framework for identifying the release of these carbonaceous species into the atmosphere from biomass combustion.

Figure 1 shows a flow diagram of the extraction, separation, and quantitation procedures used to determine the elutable organics fraction (i.e., solvent-soluble organic compounds that are detected by HRGC). These micro-methods have been developed for the quantitative recovery of extractable organic matter contained in the atmospheric fine aerosol fraction (i.e., aerosol particles having nominal diameters $<2.1 \mu \mathrm{m}$ ) (Mazurek et al., 1987; $1988 ; 1990 \mathrm{~b})$. Routine quality control procedures are incorporated into the methodology and include monitoring of sampling artifacts, analysis of procedural blanks, and an accounting of analyte recovery. The organics are extracted from the filters by ultrasonic agitation using 
successive additions of hexane ( 2 volume additions) and benzene/isopropanol ( 3 volume additions). The serial extracts are filtered and then combined. The total extracts are reduced to volumes of 200 to $300 \mu \mathrm{L}$. The neutral fraction of the elutable organics is defined operationally as that fraction which elutes from the bonded phase (DB-1701) of the analytical column and is detected by the flame ionization detector (FID) of the HRGC without further derivatization. An aliquot of the total extract is derivatized by addition of diazomethane (Mazurek et al., 1987). This step converts reactive organic acids to the respective methyl ester or methyl ether analogues. Injection of the derivatized fraction onto the HRGC column produces chromatographic data for the acid plus neutral (acid+neutral) fraction. The mass of the acid fraction of the elutable organics is calculated by difference.

Quantitation of the elutable organics fraction is accomplished by computerized HRGC analyses that combine: (1) area counts relative to a coinjection standard (1-phenyldodecane); (2) relative response factors for the perdeuterated surrogate standard $\left(n-C_{24} D_{s_{0}}\right)$; and (3) recoveries of the surrogate standard. Sampling and analytical procedural artifacts are monitored by high-resolution gas chromatography/mass spectrometry (HRGC/MS) analysis. This quality control/quality assurance step screens contributions of possible common sampling contaminants such as plasticizers, rubber stabilizers, silicone greases, lubricating greases, and oils (Mazurek et al., 1988). Overall, the analytical protocol for the elutable organics fraction is designed to provide quantitative results which are adjusted for any losses associated with volatilization, incomplete extraction, or instrumental bias, and for any additions of sampling or analytical organic artifacts. 


\section{RESULTS AND DISCUSSION}

\section{Smoke Aerosol Bulk Carbon}

Ambient mass concentrations for the total, organic, and elemental carbon components of the smoke aerosols are summarized in Table 1. Mass loadings per filter are given to allow comparison with the travel blank mass levels for the same carbon species. The travel blank contains low levels of TC ( $27 \mu \mathrm{g} /$ filter); the carbon present is in the form of $\mathrm{OC}$ and EC is not detected. The total carbon measured in the travel blank is small (2-4\%) compared to the mass/filter loadings of total carbon found in the in-plume smoke aerosol samples. Comparison of the total carbon masses for the travel blank and the full-fire background aerosol shows a higher proportion of blank-to-sample loadings. However, it will be shown later that the major component of the full-fire background sample, the OC fraction, has a distribution profile that is distinct from that of the travel blank. Therefore, the carbonaceous material present in the full-fire background sample is composed mainly of compounds other than those found in the travel blank.

Different chemical properties for the smoke aerosol are seen in Table 1. Ambient mass concentrations for all the bulk carbon fractions are highest for the full-fire, in-plume smoke samples. These maximum ambient mass concentrations observed for TC, OC, and EC are 50 to 350 times the levels of TC and OC, and 1 to 40 times the levels of EC, that were measured for fine particulate matter (1982 annual averages) for the Los Angeles area (Gray et al., 1986). In comparison to a polluted urban atmosphere, the bulk carbon species concentrations are significantly higher for this prescribed burn event in rural Ontario, CAN. 
The distribution of OC and EC fractions within the total mass of aerosol carbon also is different for the biomass smoke aerosol and urban plume aerosol: EC accounts for less of the total carbionaceous aerosol mass in the prescribed burn aerosol studied here.

Important properties relating to the combustion conditions present during the prescribel burn can be tracked by the $\mathrm{OC}$ and $\mathrm{EC}$ ambient mass concentrations and by the OC:EC riass ratios. The vast proportion (91\% to $99 \%)$ of carbonaceous smoke aerosol is present as $O C$, regardless of the combustion temperature. Full-fire conditions produce the greatest ambient mass concentration of $\mathrm{OC}$ aerosol and are 2 to 4 times the ambient mass levels measured during smoldering fire conditions. Formation of EC particles is greatest during fill-fire combustion relative to smoldering combustion. Elemental carbon ambient mass concentrations are similar for the two full-fire samples $\left(120\right.$ to $\left.160 \mu \mathrm{g} / \mathrm{m}^{3}\right)$, but vary over a wider range during smoldering conditions $\left(6\right.$ to $\left.50 \mu \mathrm{g} / \mathrm{m}^{3}\right)$. The relative mass distribution of organic carbon to elemental carbon within the smoke aerosol can be followed by the DC:EC mass ratios shown in Table 1. The OC:EC ratios have a range of 10 to 95 for all smoke aerosols sampled; full-fire smoke plume aerosol have lower OC:EC ratios (10 to 18) and smoldering in-plume aerosol have higher, more variable ratios (21 to 95). The OC and EC data show nonuniform production of these particles during various stages of the prescribed bum, and major differences in the type of carbonaceous aerosol that is generated (OC versus $\mathrm{EC})$.

\section{Smoke Aerosol Elutable Organics}

Elutable organics are a subfraction of the OC smoke aerosol; further separation and 
analysis of this organic mixture by HRGC provides data on the chemical composition of these solvent-soluble compounds. Figures $2 \mathrm{a}-2 \mathrm{~d}$ show the HRGC plots of the elutable organics found in the aerosol samples and the travel blank. With the exception of the travel blank, the HRGC plots of the elutable organics are complex mixtures of individual organic compounds. Separate injections and analyses of an $n$-alkane standard mixture run under identical HRGC conditions have shown that the elutable organics distributions reproduced in Figure 2 are comprised of organic compounds having 6 to 40 carbon atoms. In contrast, elutable organics present in the travel blank (plus analytical blank) show a very simple profile having few components that contain 6 to 25 carbon atoms. The species distribution of elutable organics present in the travel blank (Figure 2d) confirms the low background levels of the bulk carbonaceous materials (TC, OC, and EC as measured by combustion analysis) that are contributed from sources relating to sample handling and storage, and to sample analysis.

The ambient mass concentrations of elutable organics measured in the aerosol samples and the travel blank are given in Table 2. The full-fire and smoldering in-plume concentrations presented in Table 2 are two orders of magnitude greater than those for the urban Los Angeles ambient aerosol samples (1982 monthly averages) that were processed in a similar fashion (Mazurek et al., 1989; Hildemann 1990). One third of the total Carbonaceous aerosol mass is composed of elutable organics (acid + neutral fraction) for both the full-fire and smoldering in-plume smoke aerosol samples. An even higher proportion of total carbonaceous aerosol mass (77\%) is composed of elutable organics (acid + neutral fraction) for the full-fire background aerosol. A breakdown of the neutral and acidic species 
present as elutable organics for the full-fire and smoldering in-plume aerosol (measured by HRGC analysis) shows complex organic acids accounting for nearly $20 \%$ of the elutable organics ambient mass concentrations. The full-fire background aerosol and the travel blank sample are composed essentially all of neutral organic compounds. These data for the prescribed burn studied indicate that massive concentrations of elutable organics are emitted during full-fire and smoldering fire conditions. Such large concentrations of organics (180 to $600 \mu \mathrm{g} / \mathrm{m}^{3}$ ) may be important precursors in the production of high ozone levels which are commonly found during biomass burning (e.g., Evans et al., 1977; Stith et al., 1981; Andreae 1990). So in addition to affecting atmospheric optical properties, emissions of elutable organics may also influence photochemical processes (oxidant production) within the earth's troposphere.

\section{CONCLUSIONS}

Carbonaceous particles are produced at nonuniform rates tor the prescribed burn studied. The ambient mass concentrations for the particulate carbon smoke aerosol are highest for the full-fire burn conditions, and do vary significantly throughout the burn. Therefore, collection strategies must define ranges in smoke aerosol concentrations that are produced. The mass distributions of the $\mathrm{OC}$ and EC fractions which comprise the total mass of particulate carbon plume aerosol, also change with combustion temperature. Highest EC concentrations are observed under full-fire conditions. However, the vast proportion of smoke aerosol carbon is in the form of $O C$ particles, regardless of the fire temperature. These $\mathrm{OC}$ and $\mathrm{EC}$ ambient mass concentrations show the relativc mass distributions of light 
scattering (OC particles) versus light scattering and absorbing (EC particles) carbonaceous smoke aerosols. Formation of light scattering $O C$ particles is a significant process for the prescribed bum studied.

\section{ACKNOWLEDGEMENTS}

This work was conducted under Contract Nc. DE-AC02-76CH00016 with the U.S.

Department of Energy under the Atmospheric Chemistry Program within the Office of Health and Environmental Research. 


\section{REFERENCES}

Andreae, M. O., E. V. Broweil, M. Garstang, G. L. Gregory, R. C. Harriss, G. F. Hill, D. L. Jacob, M. C. Pereira, G. W. Sachse, A. W. Setzer, P. L. Silva Dias, R. W. Talbot, A. L. Torres, and S. C. Wofsy, Biomass-burning emissions and associated haze layers over Amazonia, J. Geophys. Res., 93, 1509-1527, 1988.

Andreae, M. O., Biomass buming: its history, use and distribution and izs impact on environmental quality and global climate, in Chapman Conference on Global Biomass Burning: Atmospheric, Climatic, and Biospheric Implications Proceedings, Williamsburg, VA, March 19-23, 1990, edited by J. S. Levine, MT Press, Cambridge, MA (this volume).

Cachier, H., M.-P. Bremond, and P. Buat-Menard, Carbonaceous aerosols from different tropical biomass burning sources, Nature, 340, 371-373, 1989.

Cachier, H., P. Buat-Menard, M. Fontugne, and R. Chesselet, Long-range transport of continentally-derived particulate carbon in the marine atmosphere: evidence from stable isotope studies, Tellus, 38B, 161-177, 1986.

Cofer, III, W. R., J. S. Levine, D. I. Sebacher, E. L. Winstead, P. J. Riggin, J. A. Brass, and V. G. Ambrosia, Particulatue emissions from a mid-latitude prescribed chaparral fire, J. Geophys. Res., 93, 5207-5212, 1988.

Duce, R. A., Speculations on the budget of particulate vapor phase non-methane organic carbon in the global troposphere, Pageoph., 116, 244-273, 1978.

Evans, L. F., I. A. Weeks, A. J. Eccleston, and D. R. Packham, Photochemical ozone in smoke from prescribed buming of forests, Environ. Sci. Technol., 11, 896-900, 1977.

Gray, H. A., G. R. Cass, J. J. Huntzicker, E. K. Heyerdahl, and J. A. Rau, Characteristics of atmospheric organic and elemental carbon particle concentrations in Los Angeles, Environ. Sci. Technol., 20, 580-589, 1986.

Gray, H. A., G. R. Cass, J. J. Huntzicker, E. K. Heyerdahl, and J. A. Rau, Elemental and organic carbon particle concentrations: a long-term perspective, Sci. Total Environ., 36, 17-25, 1984.

Hildemann, L. M., A Study of the Origin of Atmospheric Organic Aerosols, Ph. D. Thesis, California Institute of Technology, Pasadena, CA, 1990. 
Johnson, R. L., J.J. Shah, R. A. Cary, and J. J. Huntzicker, An automated thermal-optical method for the analysis of carbonaceous aerosol, in ACS Symp. Series No. 167, Atmospheric Aerosol: Source/Air Quality Relationships, edited by E. S. Macias and P. K. Hopke, American Chemical Society, Washington, DC, 1981.

Mazurek, M. A., G. R. Cass, and B. R. T. Simoneit, Quantification of the Source Contributions to Organic Aerosols in the Remote Desert Atmosphere, final report to Electric Power Research Institute, Califomia Institute of Technology, Pasadena, CA, 1988.

Mazurek, M. A., G. R. Cass, and B. R. T. Simoneit, Interpretation of high-resolution gas chromatography and high-resolution gas chromatography/mass spectrometry data acquired from atmospheric organic aerosol samples, Aerosol Sci. Technol., 10, 408$420,1989$.

Mazurek, M. A., L. M. Hildemann, G. R. Cass, B. R. T. Simoneit, and W. F. Rogge, Measurement and flux of carbonaceous aerosol species from pine and oak combustion, paper presented at Chapman Conference on Global Biomass Burning: Atmospheric, Climatic, and Biospheric Implications Proceedings, Williamsburg, VA, March 19-23, 1990a.

Mazurek, M. A., L. M. Hildemann, G. R. Cass, B. R. T. Simoneit, and W. F. Rogge, Methods of analysis for complex organic mixtures from urban sources of particulate carbon, ACS Symp. on Measurement of Airborne Compounds: Sampling, Analysis, and Data Interpretation, Proceedings, Washington, D. C., August 26-31, 1990, edited by E. D. Winegar and L. H. Keith, Lewis Publishers, Chelsea, MI, $1990 \mathrm{~b}$.

Mazurek, M. A., B. R. T. Simoneit, G. R. Cass, and H. A. Gray, Quantitative highresolution gas chromatography and high-resolution gas chromatography/mass spectrometry analyses of carbonaceous fine aerosol particles, Intern. J. Environ. Anal. Chem., 29, 119-139, 1987.

Seiler, W. and P. J. Crutzen, Estimates of gross and net fluxes of carbon between the biosphere and the atmosphere from biomass burning, Climatic Change, 2, $207-$ $247,1980$.

Standley, L. J. and B. R. T. Simoneit, Characterization of extractable plant was, resin, and thermally matured components in smoke particles from prescribed burns, Environ. Sci. Technol., 21, 163-169, 1987.

Standley, L. J. and B. R. T. Simoneit, Preliminary correlation of organic molecular tracers in residential wood smoke with the source of fuel, Atmos. Environ., 24B, 67-73, 1990. 
Stith, J. L., L. F. Radke, and P. V. Hobbs, Particle emissions and the production of ozone and nitrogen oxides from the burning of forest slash, Amos. Environ., 15, 73-82, 1981.

Stocks, B., private communication, 1990.

Suman, D. O., The flux of charcoal to the troposphere during the period of agricultural buming in Panama, J. Atmos. Chem., 6, 21-34, 1988. 


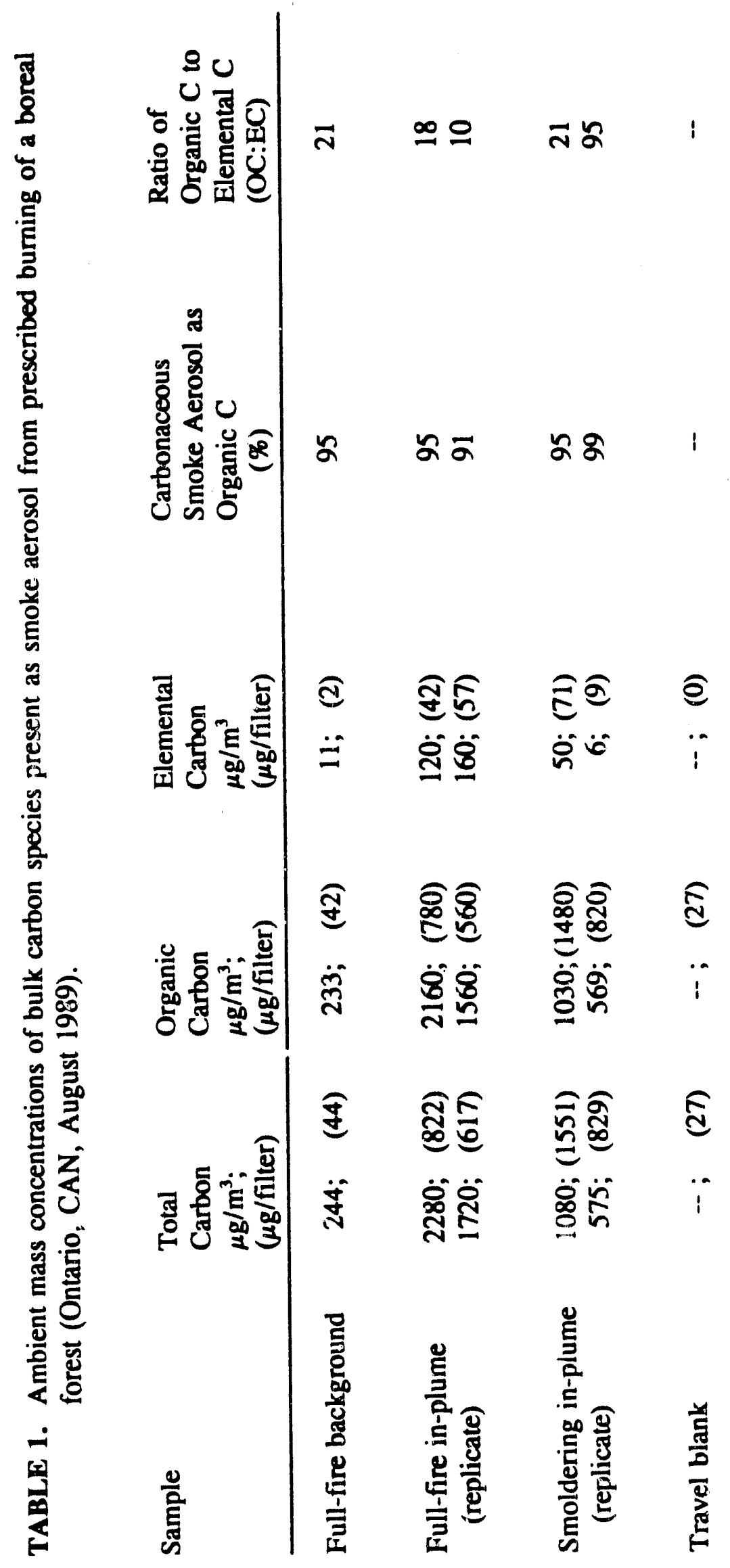




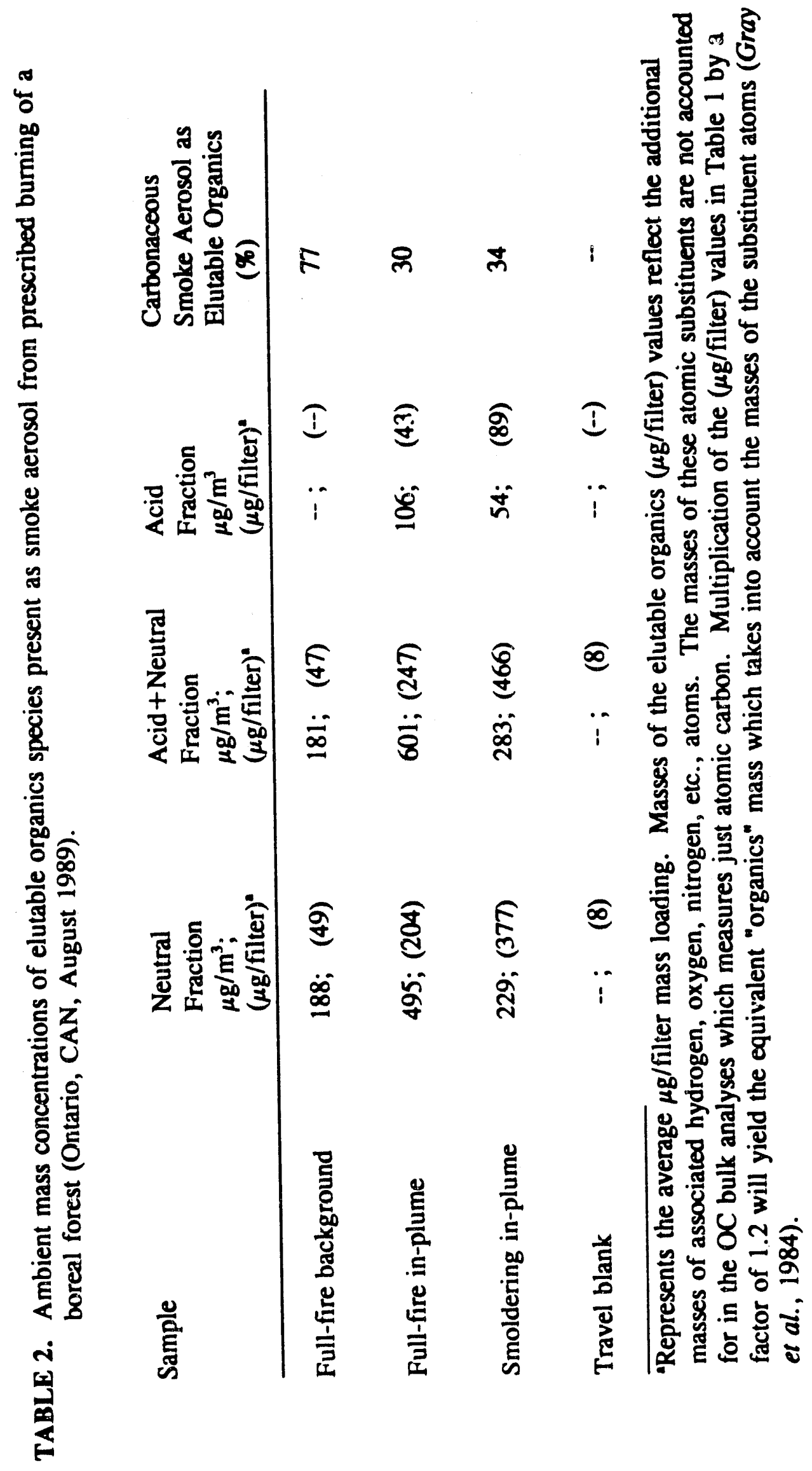




\section{FIGURE CAPTIONS}

Figure 1. Flow diagram of the methods used for the extraction, quantitation, and characterization of elutable organic aerosol components.

Figure 2. HRGC plots of the elutable organics from (a) full-fire background aerosol (acid + neutral fraction); (b) full-fire in-plume aerosol (acid + neutral fraction); (c) smoldering in-plume aerosol (acid + neutral) fraction; and (d) travel blank (acid+neutral fraction). The solid circle indicates the peak corresponding to the surrogate standard ( $n-C_{24} D_{s 0}$; retention time $=32$ minutes). 


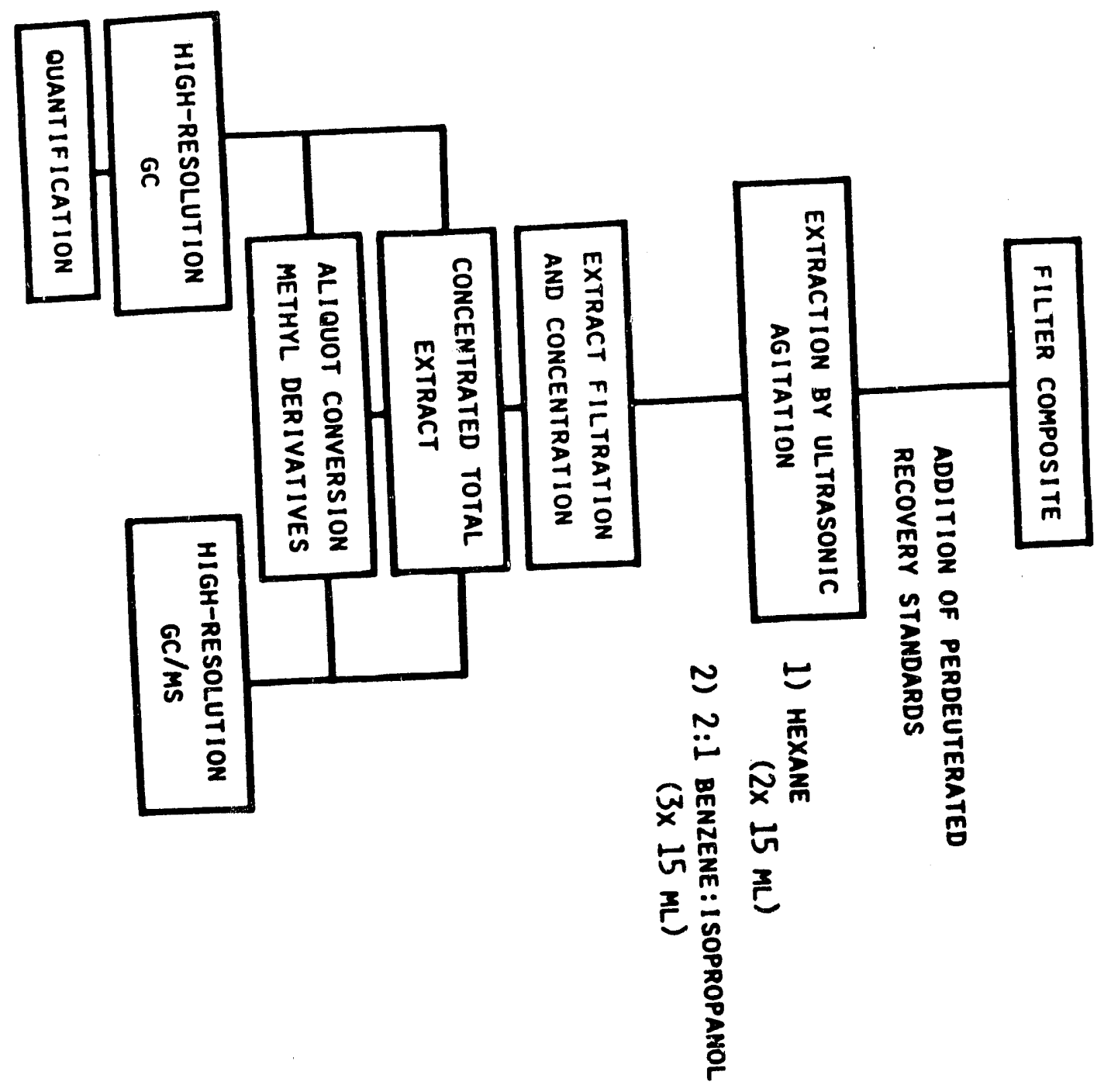



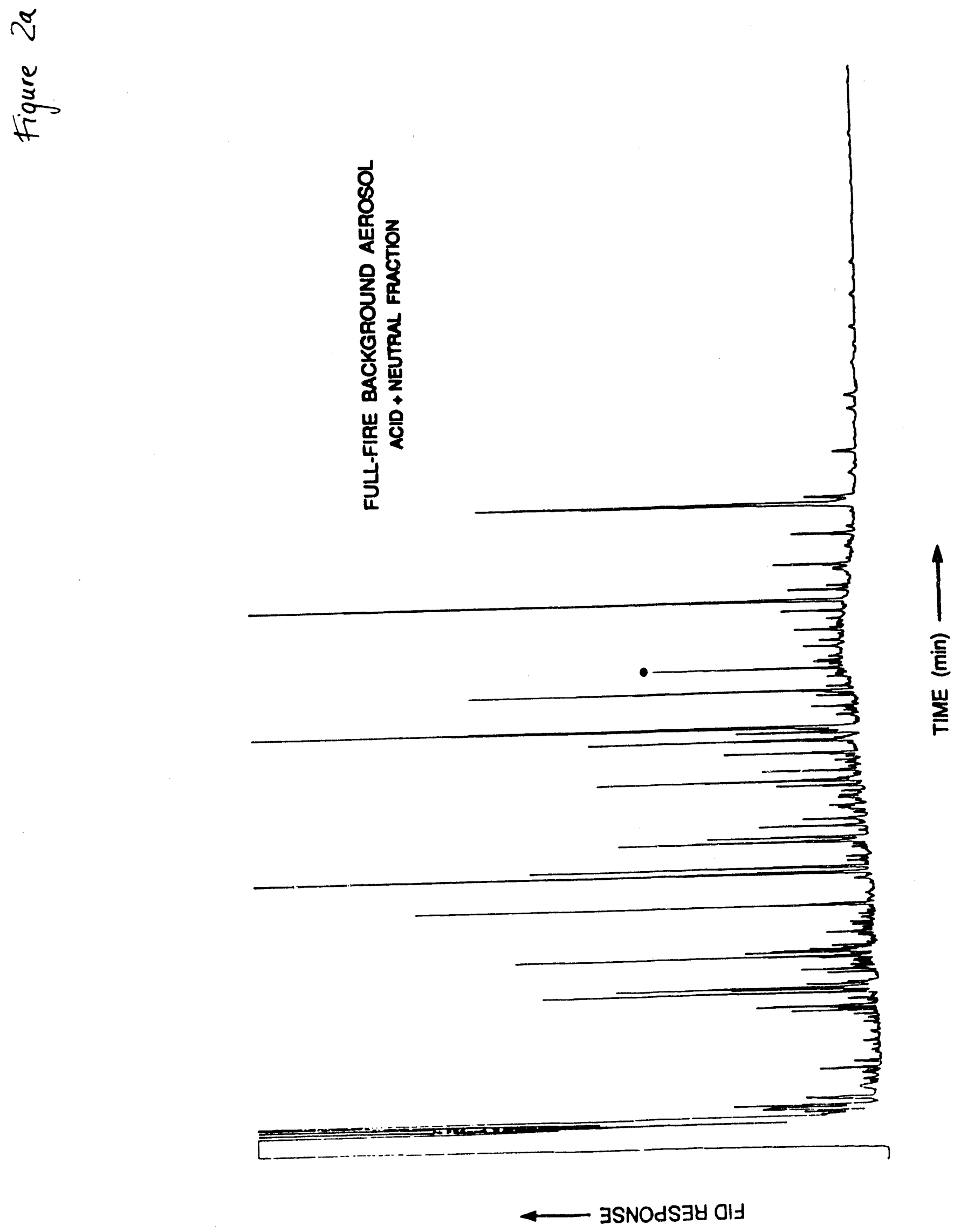
8

密
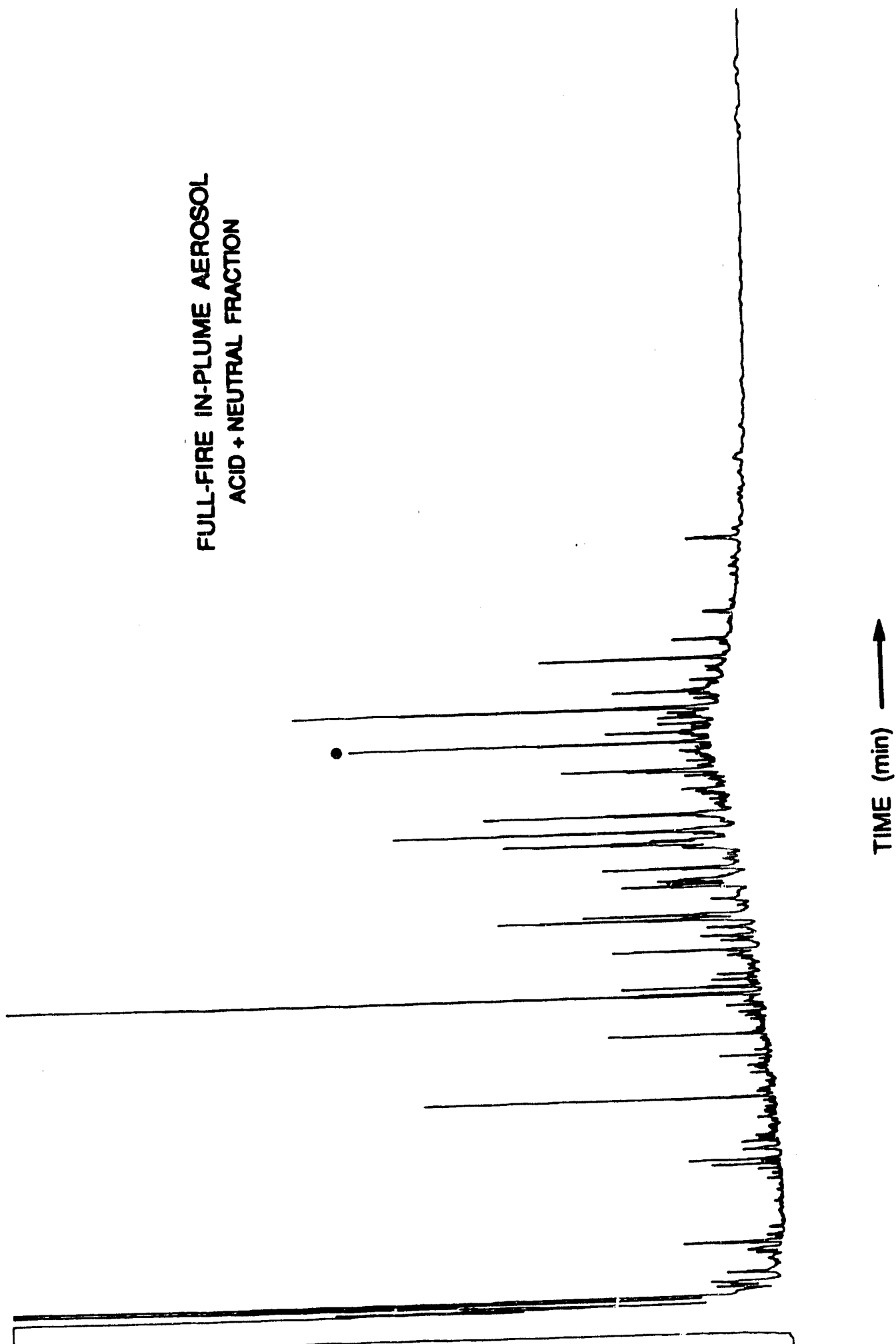

BSNOdS 34 als 
v
ปू.

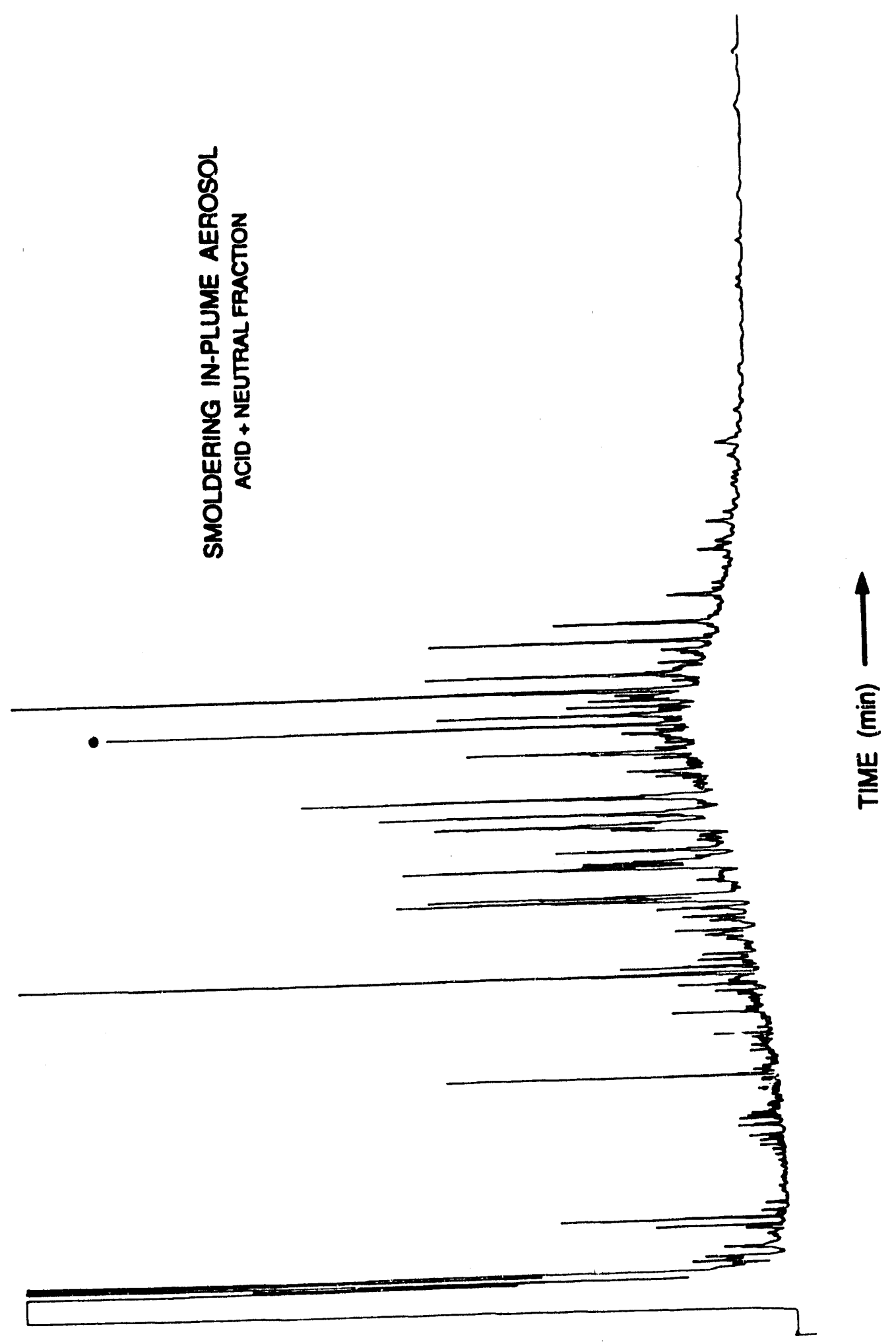

JSNOdS $\exists$ Y aly 
v

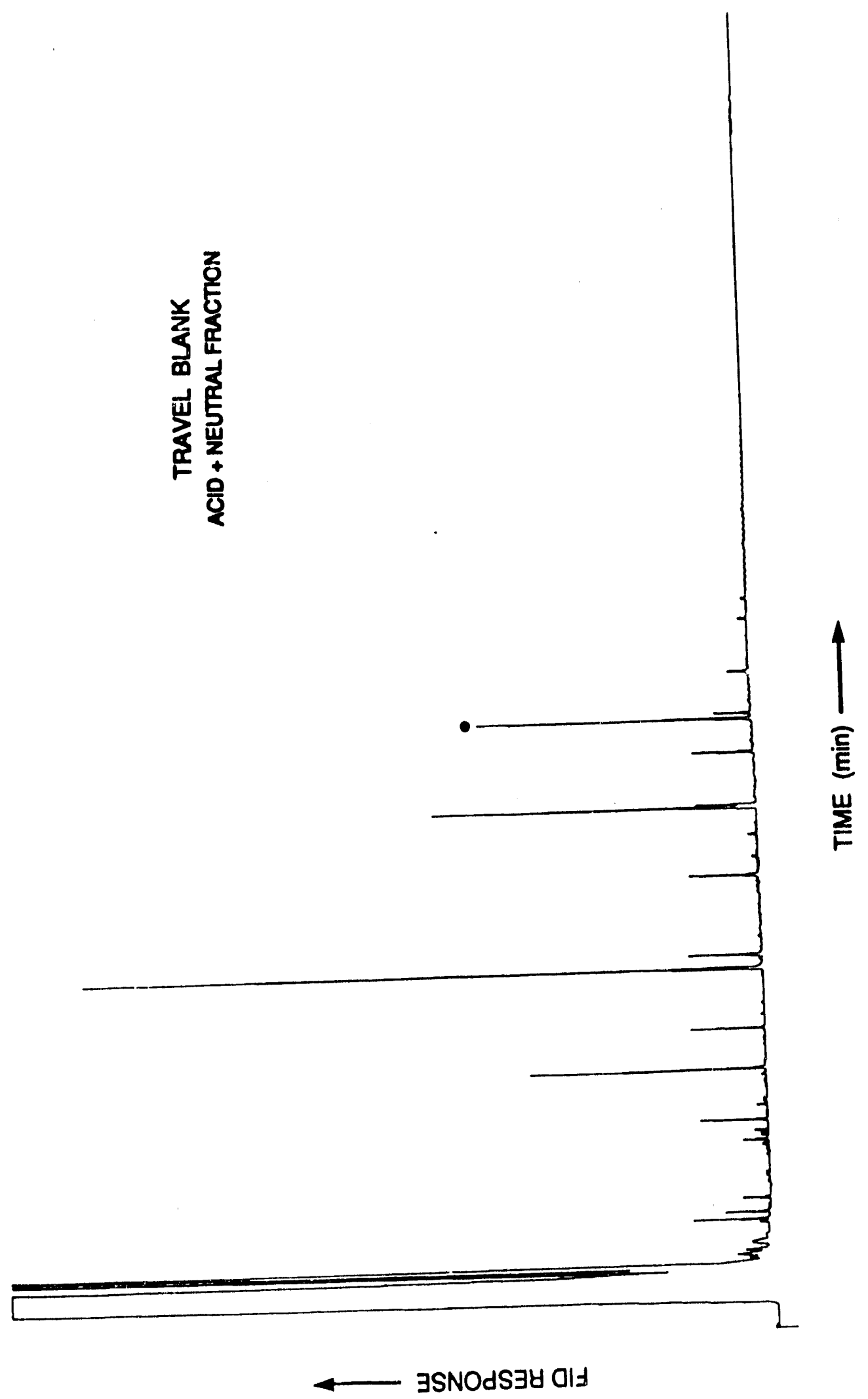



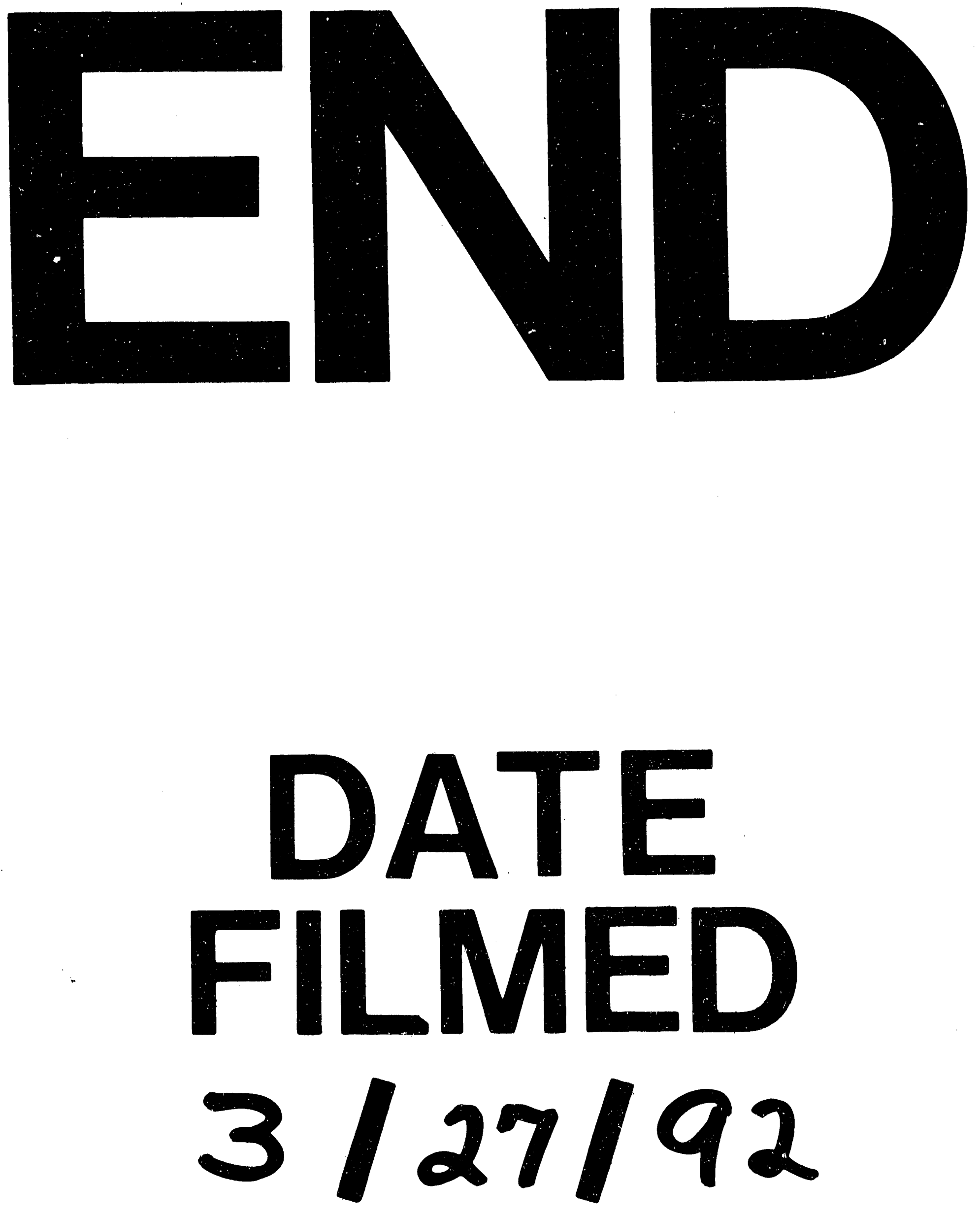


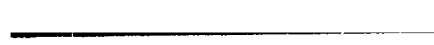

